\title{
A DISCRETE EVENT MODELLING APPROACH FOR SUPPLY CHAIN SIMULATION
}

\author{
Wang, Q.* \& Ingham, N.** \\ * School of Engineering, Durham University, Durham, DH1 3LE, United Kingdom \\ ${ }^{* *}$ Baker Tilly, Guildford, GU1 1UW, United Kingdom \\ E-Mail: qing.wang@durham.ac.uk; npcingham@gmail.com
}

\begin{abstract}
In today's competitive environment, companies face increasingly diverse challenges. To survive in the next millennium, they need to improve their profit margins by cutting capital costs and creating more responsive and adaptable supply chains to meet the ever changing market demand. This paper aims to investigate how dynamic simulation tools can be used to improve and optimise supply chain performance. The general overview of the supply chain is first introduced, the importance of order release mechanisms is examined and its use as a performance measure to monitor the supply chain is proposed. Simulations were developed to investigate the customer/manufacturer relationship of the supply chain. After the running of the trials a diagnostic evaluation was formed. With the simulation results analysed, significant improvements in lowering inventory costs, increasing output and fulfilling orders on time were achieved.
\end{abstract}

(Received in August 2007, accepted in June 2008. This paper was with the authors 6 months for 2 revisions.)

Key Words: Simulation Modelling, Dynamic Supply Chain, Order Release Mechanisms

\section{INTRODUCTION TO SUPPLY CHAIN}

A supply chain can be described as any sequence of processes involved in the production and distribution of a commodity and is generally in the format as shown in Fig. 1. Each component in the supply chain is connected to other parts of the supply chain by the flow of materials in one direction, the flow of orders in the other and the flow of information in both directions. "Changes in any one of these components usually create waves of influence that propagate throughout the supply chain” [1]. Such waves are reflected in inventory levels [2], finished product numbers, and the movement of products and materials. How these influences propagate through the system determines the 'dynamics' of the supply chain $[3,4,5]$.

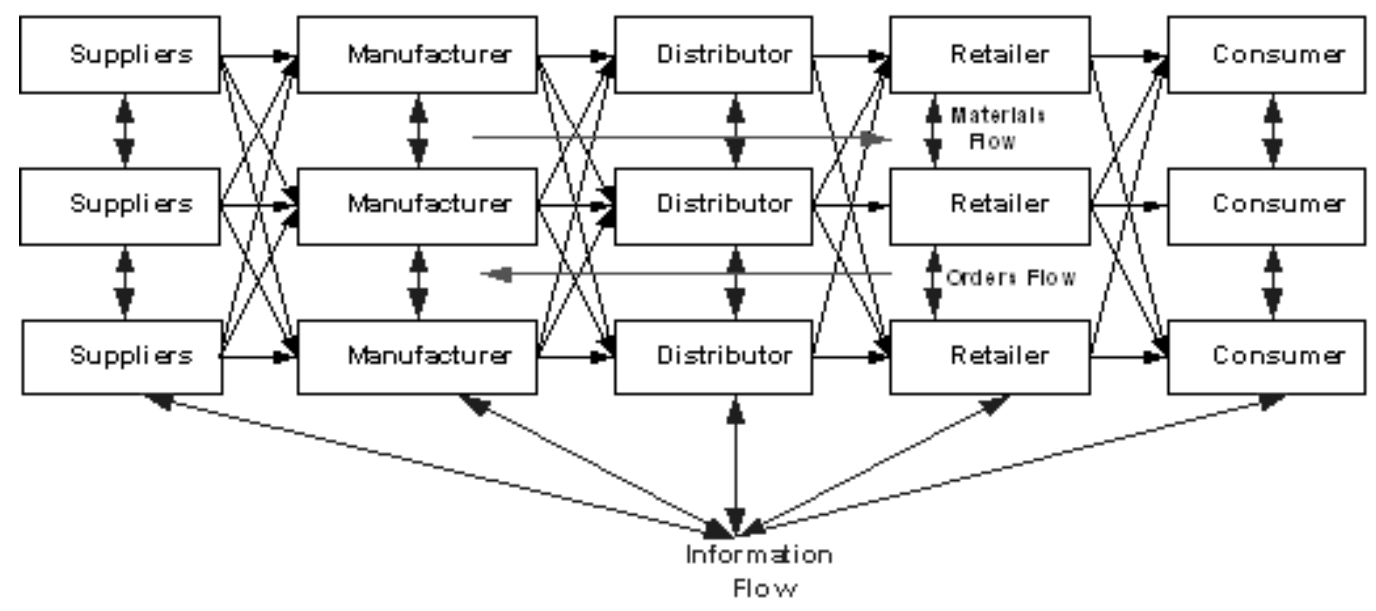

Figure 1: A Generic Supply Chain Structure. 
As the supply chain network is a complex system, several of the problems within it can be generated in the areas of supplier selection, logistic function, production planning and control, inventory management, etc. Table I summarises the current key supply chain research areas and the contributed researchers respectively.

Table I: Key Supply Chain research areas within the Literature.

\begin{tabular}{|l|l|}
\hline Supply Chain Research Areas & Authors \\
\hline $\begin{array}{l}\text { Inventory Management, Vendor Managed } \\
\text { Inventory (VMI), Raw material related } \\
\text { policies }\end{array}$ & $\begin{array}{l}\text { Hafeez et al. [6], Holmström [7], Parija } \\
\text { and Sarker [8], Yang and Wee [9], } \\
\text { Cheung and Leung [10] }\end{array}$ \\
\hline $\begin{array}{l}\text { Information Sharing / Coordination } \\
\text { Mechanism }\end{array}$ & $\begin{array}{l}\text { Zhao and Xie [11], Klastorin et al. [12], } \\
\text { Ertogral and Wu [ 13], Qinghe et al [14] }\end{array}$ \\
\hline Production Planning and Control & $\begin{array}{l}\text { Dogan and Goetschalckx [15], Korpela et } \\
\text { al [16], Khouja [17], Munson and } \\
\text { Rosenblatt [18], Lee et al. [19] }\end{array}$ \\
\hline Vendor Selection, Intermediaries & $\begin{array}{l}\text { Agrawal and Seshadri [20], Karpak, et al. } \\
\text { [21] }\end{array}$ \\
\hline Product and Process Design & Persson and Olhager [22], Garg [23] \\
\hline
\end{tabular}

Each research area has main entities to look at, for example inventory management and raw material related policy are mainly used by the suppliers and manufacturers. VMI is normally considered between distributors and manufacturers. Production planning and control usually happens between manufacturers and suppliers. Product and process design originates from retailers and affects distributors. There is a trend in recent years that a supply chain should be considered as a whole to form a network rather than a sequential chain. The matrix described in Table II shows the relationship between supply chain research areas and their entities.

Table II: Relationships between Supply Chain research areas and entities (adapted from [24]).

\begin{tabular}{|l|c|c|c|c|}
\hline & Retailers & Distributors & Manufacturers & Suppliers \\
\hline $\begin{array}{l}\text { Inventory management, raw } \\
\text { material related policies }\end{array}$ & & & $\sqrt{ }$ & $\sqrt{ }$ \\
\hline VMI & & $\sqrt{ }$ & $\sqrt{ }$ & $\sqrt{ }$ \\
\hline Production planning and control & & & $\sqrt{ }$ & \\
\hline $\begin{array}{l}\text { Vendor Selection, } \\
\text { Intermediaries }\end{array}$ & & & $\sqrt{ }$ & $\sqrt{ }$ \\
\hline Product and process design & $\sqrt{ }$ & & $\sqrt{ }$ & \\
\hline $\begin{array}{l}\text { Information sharing / } \\
\text { coordination mechanism }\end{array}$ & $\sqrt{ }$ & $\sqrt{ }$ & & \\
\hline
\end{tabular}

In recent years, material flow control or order release problems have become increasingly important to both researchers and practitioners. As a result of this, many authors use the criterion of minimising work in progress (WIP) to reduce the labour and materials cost. Furthermore, reducing WIP will lead to reducing the lead time and Crandall and Burwell [25] have confirmed this in their paper. The benefit of shortening lead times can reflect the service to the customer, therefore influencing the order release mechanism [26]. The main order release mechanisms are shown in Fig. 2 with 4 different scenarios: 
- Case 1: Order arrives at variable period with variable quantity:

Under this scenario a new order will be released based on the customer demand. No planning has been made and it is independent of current inventory levels.

- Case 2: Order arrives at fixed period with variable quantity:

This is a period planning process and commonly recognised as material requirement planning (MRP). In this scenario, MRP was created to tackle the problem of 'dependent demand'. An order will be released based on knowing the finished products. It is assumed there is sufficient capacity available, lead times are known or can be estimated and the time period is fixed.

- Case 3: Order arrives at variable period with fixed quantity:

This is an advanced planning and scheduling method. This method can plan orders immediately upon receipt. By checking the inventory levels, the schedule for manufacturing batches of a fixed quantity can be determined. The movement of these fixed batches in the supply chain network is constantly monitored and results in shorter lead times and increased throughput.

- Case 4: Order arrives at fixed period with fixed quantity:

In this situation the number of orders in the system is maintained constant and the order is released within a fixed time period. The drawback of this type of order release is that it doesn't consider any system changes which could lead to a bottleneck logistic function and therefore may have a significant impact on the overall performance of the supply chain.

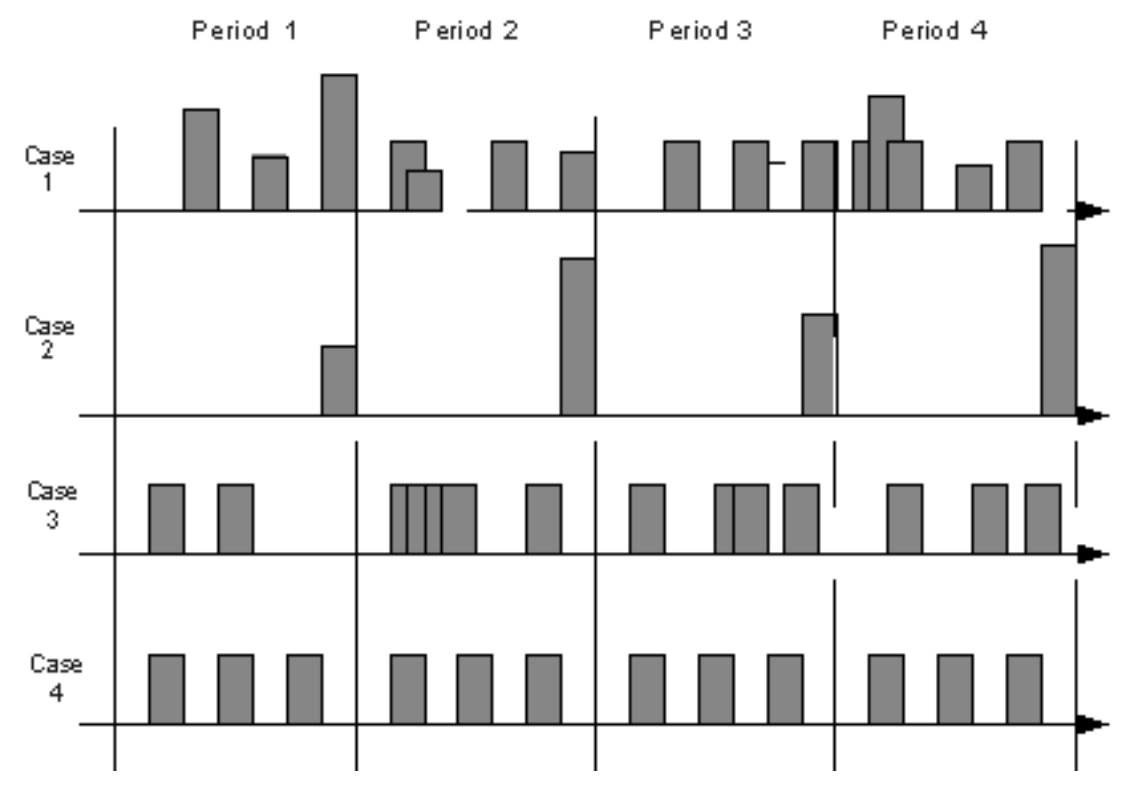

Figure 2: Order releases and batching.

There are many reasons why these effects occur, especially within an integrated supply chain. There are also many solutions to each supply chain problem. The research into the supply chain simulation is to understand the dynamics of the system and minimise the inefficiencies in the system.

\section{SIMULATION}

The term 'simulation' is defined as the process of creating a conceptual computer model that can adequately represent the behaviour of an existing or proposed system in order to identify and understand the factors that control the system [1]. Simulation research has been found in a 
wide range of application areas such as a manufacturing supply chain [27], construction supply chain [28] and semiconductor supply chain [29] etc.

If the future were predictable then managing a supply chain would be straightforward. However, in reality the future is uncertain [30] and therefore a supply chain must be flexible and fully capable of adjusting to a wide range of potential futures [31, 32]. Dynamic simulation [33] is a valuable tool to test proposed strategies in an unpredictable environment such as a multi-tiered supply chain. It has two characteristics: (1) it represents a discrete event and (2) it uses a stochastic method and therefore incorporates uncertainties.

A simulation program known as Simul8 [34] is used in this research. It is important to realise where Simul8 fits in with other technical solutions available to supply chain managers. Enterprise Resource Planning (ERP) is most commonly used at operational level and helps to acquire processes and communicate information regarding the past and present, and fits into what is known as transactional IT. In contrast to this, Simul8 fits into the area of analytical IT concerned with forecasting, decision making and problem solving. Such systems as described in Fig. 3 should ideally be integrated so that programs such as Simul8 can benefit from the information collected from transitional IT-like ERP systems.

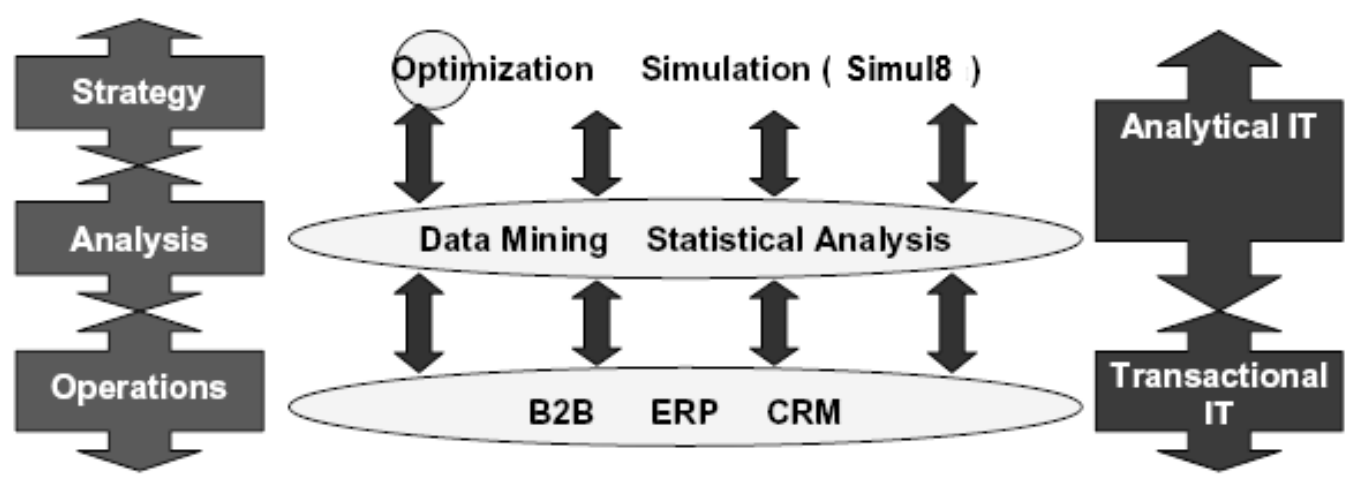

Figure 3: Classification of IT solutions (adapted from [1]).

\section{SIMULATION TASKS}

\subsection{Planning Relevant Simulations}

To create relevant and well structured simulations [35] that investigate the effect and performance variation of certain management solutions for a manufacturing supply chain [36, 37], the following plan was adhered to:

- Clear objectives: Establishing clear objectives involves reviewing and clearly stating the objectives and goals of the exercise, whether the supply chain had problems to address or areas of known inefficiency in their operations.

- Fragmentation: It is important to understand that a Simul8 simulation model will not provide useful information if it isn't based upon the supply chain system it is analysing. The greater the understanding of the critical factors that lie behind the supply chain which determine the behaviour of the system, the more likely the simulation will provide relevant and accurate results.

- Integration: This step usually requires input and feedback from people within an organisation in order to establish what the properties of each process are and how each process is coupled with another.

- Simple model with added detail: Models of great detail can be difficult to maintain, alter and get working accurately and therefore it was decided that, for each main performance issue 
addressed, a separate but linked simulation would be created and modifications would be built on top of a base setup. Detail to the processes and their interactions should only be added to investigate a particular problem or detail in the supply chain as and when considered relevant.

- Uncertainty and dynamic simulation: Build into the simulation and account for any contingency plans the supply chain has to combat variations or disruptions in the supply chain $[38,39]$.

\subsection{The Simulations}

In order to formalise the supply chain, forecasting is normally used to estimate the demand at each stage within the supply chain. This information determines the inventory levels that need to be held between network stages in order to provide protection against fluctuations in supply and demand that may occur across the network. Such fluctuation can be raised by unexpected machine breakdown, large demand in short periods, or poorly designed processes that lead to the bullwhip effect, which is the main reason for inefficiencies in supply chains. Buchmeister [40] investigates the bullwhip effect by using spreadsheet simulations and the results show that it can be partially reduced by appropriate stock keeping policy. It is believed that under the pressure of globalization, shortening of product life cycles and increasing variability in customer demand, could result in the use of inventory as protection against such variability. However the adaptation of this strategy has resulted in high costs and reduction in supply flexibility.

Where possible, therefore, inventory should be 'replaced' by information. Actual customer demand information should therefore be the only information that provides signals for initiating the manufacturing process. This would allow the decentralised control property of supply chain networks to be maintained by providing planning co-ordination between entities in performing their tasks. In order to achieve this, actual customer demand information would need to be broadcast to the entire supply chain network on a timely basis as depicted in Fig. 1.

In general, modelling methods in supply chains can be divided into two major categories analytical approach and simulation approach. For the analytical approach the majority of the research is focussed on investigating the different clean functions to represent the relationship between the expected output during a certain production period and the expected work in progress at the inventory level during that period [41]. Due to the complex scenarios appearing in the supply chain planning process, the analytical approach to planning seems infeasible in situations where the number of variables and possible alternatives to evaluate is large. Therefore a simulation model has been developed in order to examine the possible performance changes that could arise from the use of new operating policies enabled by faster planning and information sharing. The simulation model has been designed to examine the influence of a core business process, i.e. the order fulfilment process. The main goal of the order fulfilment process is to guarantee timely deliveries of goods despite the variability in external (e.g. customer order arrival times and quantities), and internal, (e.g. breakdown intervals and repair times) environments.

This simulation was built to represent customer/manufacturer relationships and the various re-order methods that can be adopted to produce a successful and adaptable supply chain. The basic structure of the simulation described in this paper consists of two customers, order planning and control units, and a three-tiered manufacturing network where the flow of products and information exist between them. The simulation model with product flow is described in Fig. 4. While the information is represented as a work item just like a product, it often travels in the opposite direction to the product flow. 


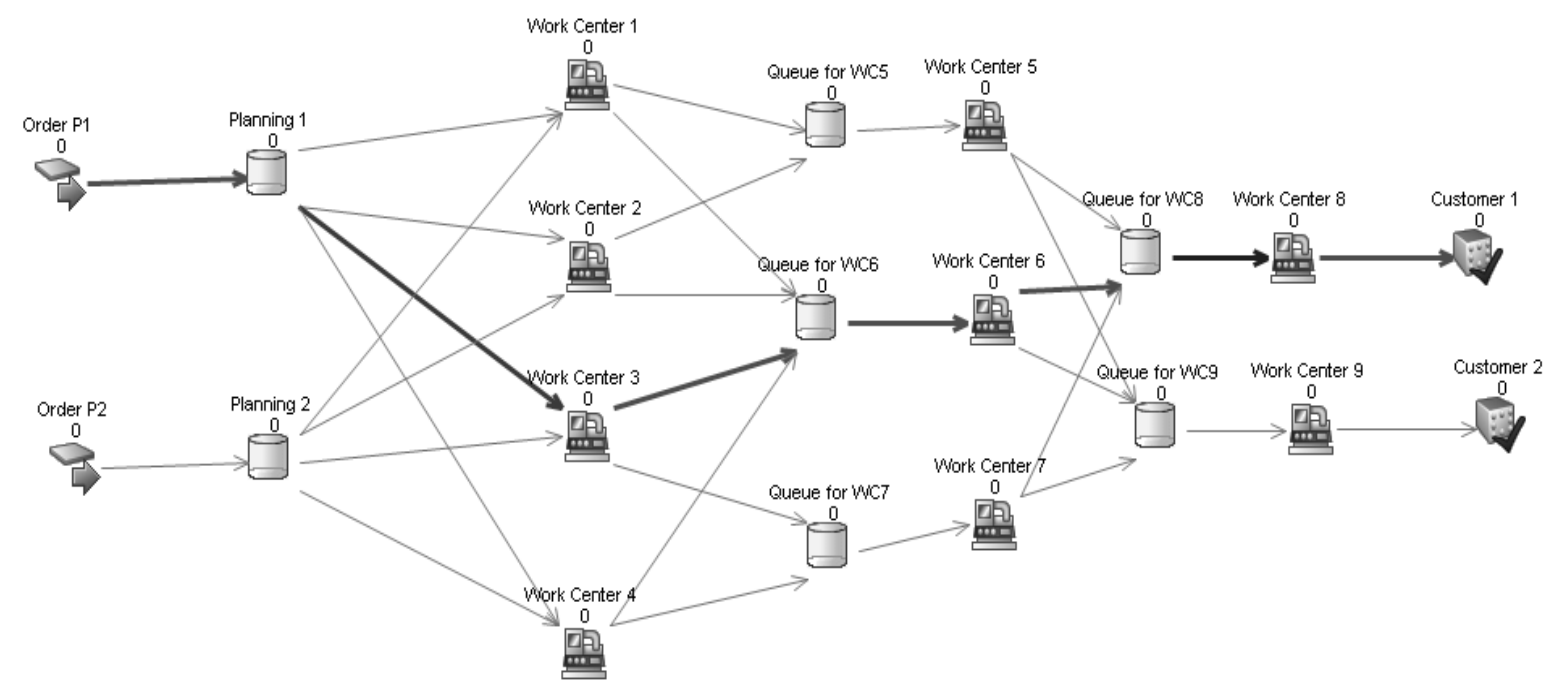

Figure 4: Simulation model to describe the Customer/Manufacturer relationships.

Orders $P 1$ and $P 2$ are accepted and processed by Planning 1 and Planning 2 which then determine the best route for each work centre to take. All routes for item $P 1$ are depicted in Fig. 5 and for item P2 in Fig. 6.

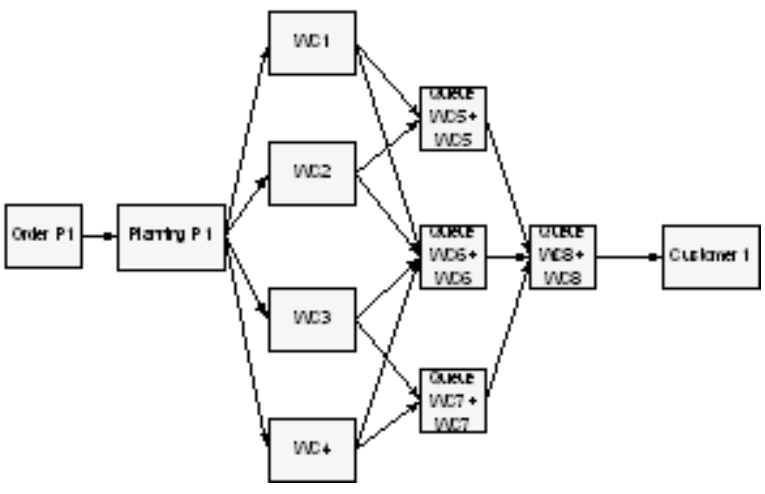

Figure 5: P1 routes.

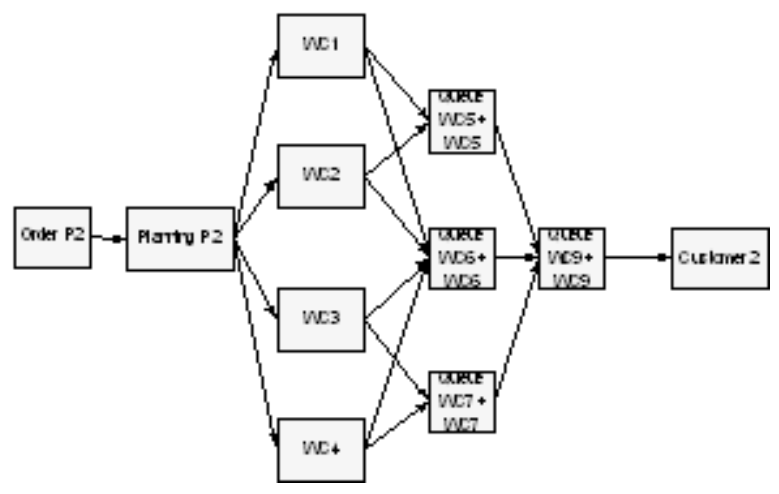

Figure 6: $\mathrm{P} 2$ routes.

For each case, four experiments with three different levels of simulation trials are run with 5,10 , and 20 replications respectively. This adds up to 12 experiments in total. The simulated time period was two weeks of production and the model was run for 8 hours a day, 5 days a week.

In all simulation studies it is necessary to point out the assumptions made during construction of the simulation model and the environment in which it operates are as follows:

- Customer demands are pushed through the supply chain.

- External suppliers are reliable.

- Capacities are limited through out the supply chain.

- Travel time within the supply chain is zero.

- The holding cost of work items in stock is $£ 0.01$ per unit per minute in each of the inventory areas.

- The usage cost per unit in each work centre is $£ 0.50$.

- Delivery costs per unit are $£ 5$ and revenue costs per unit are $£ 10$. 


\section{SIMULATION RESULTS}

Upon running the simulation for a time period of 4800 mins, the following output data are observed and stored for analysis: number of products produced, inventory levels, queue time and work centre utilization.

\subsection{Total production}

In Table III, the number of products produced in each case can be reviewed. It is obvious that each model can produce almost exactly the same volume of products, which makes the simulation models comparable to each other. The smaller standard deviations presented in Case 1 indicate that Case 1 had less capability to adjust its production quantity when compared with other three cases and Case 3 with the largest standard deviation means it can reduce the risk if the customer demand is uncertain.

Table III: Number of products produced in each experiment.

\begin{tabular}{|l|c|c|c|}
\hline $\begin{array}{l}\text { Supply chain } \\
\text { structure }\end{array}$ & No. of trails & $\begin{array}{c}\text { Average number of } \\
\text { products produced }\end{array}$ & $\begin{array}{c}\text { Standard } \\
\text { deviation }\end{array}$ \\
\hline \multirow{3}{*}{ Case 1} & 5 & 449 & 3.87 \\
\cline { 2 - 4 } & 10 & 447 & 5.90 \\
\hline \multirow{3}{*}{ Case 2} & 20 & 449 & 6.64 \\
\cline { 2 - 4 } & 5 & 445 & 15.34 \\
\hline \multirow{3}{*}{ Case 3 } & 10 & 448 & 11.26 \\
\cline { 2 - 4 } & 20 & 447 & 12.43 \\
\hline \multirow{3}{*}{ Case 4 } & 5 & 440 & 15.86 \\
\hline & 10 & 446 & 14.64 \\
\cline { 2 - 4 } & 20 & 449 & 11.09 \\
\cline { 2 - 4 } & 5 & 446 & 14.44 \\
\hline
\end{tabular}

\subsection{Inventory level}

The inventory level was used as a second measure of the model validity. In all 4 cases, work centre 6 appears to have the highest inventory level than any other inventories, almost reaching the capacity limit which is set as 25 . It is not surprising that both $P 1$ and $P 2$ routes pass through WC5, leaving it as the busiest work centre throughout the whole supply chain with capacity designed as 25 . By looking more closely at Case 3 , it is shown that this model has fewer inventories than any other model and there is no inventory in $P 1$ and $P 2$. Fig. 7 also shows that there are unbalanced inventory controls between $P 1$ and $P 2$, even the initial capacity set up for both $P 1$ and $P 2$ is 25 . 


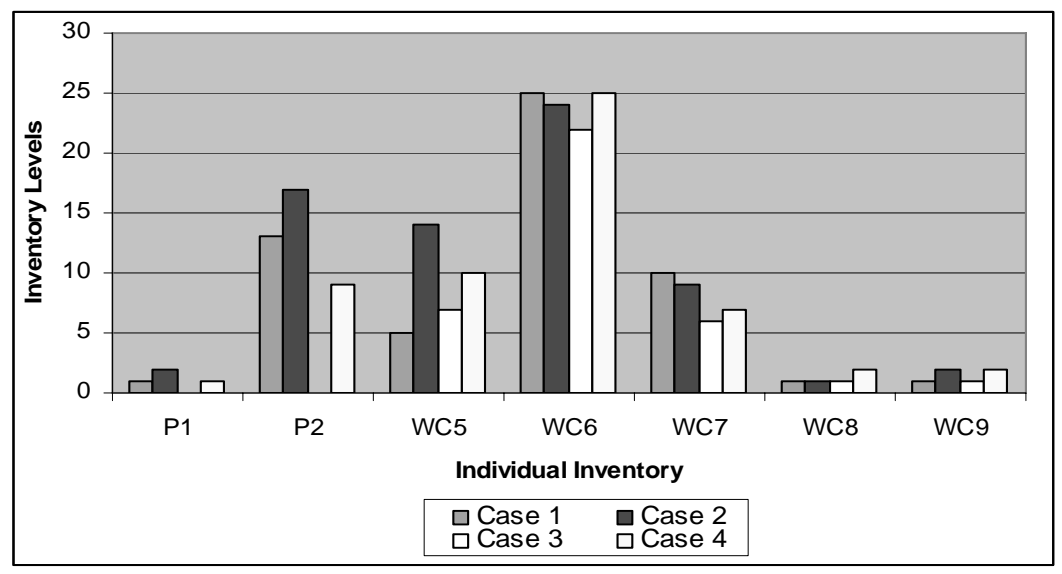

Figure 7: Total inventory comparison for the four cases.

\subsection{Queuing Time}

In this simulation study, Work Centre 5 was chosen to evaluation the queuing time as it is in the middle stage of the supply chain. The results are shown in Fig. 8. However with respect to the complexity of supply chain process, the measures that we use are calculated as the number of products leaving the work centre minus the total number of products entering the work centre, divided by the inventory capacity. This ratio will be a number between zero and one, where zero corresponds to a situation with no queuing time at a specific process stage. As can be expected, although Case 3 had the highest queuing time to start with, after 50 minutes it rapidly reduced to $15 \%$ and gradually reduced every 50 minutes until it reached zero at 250 minutes.
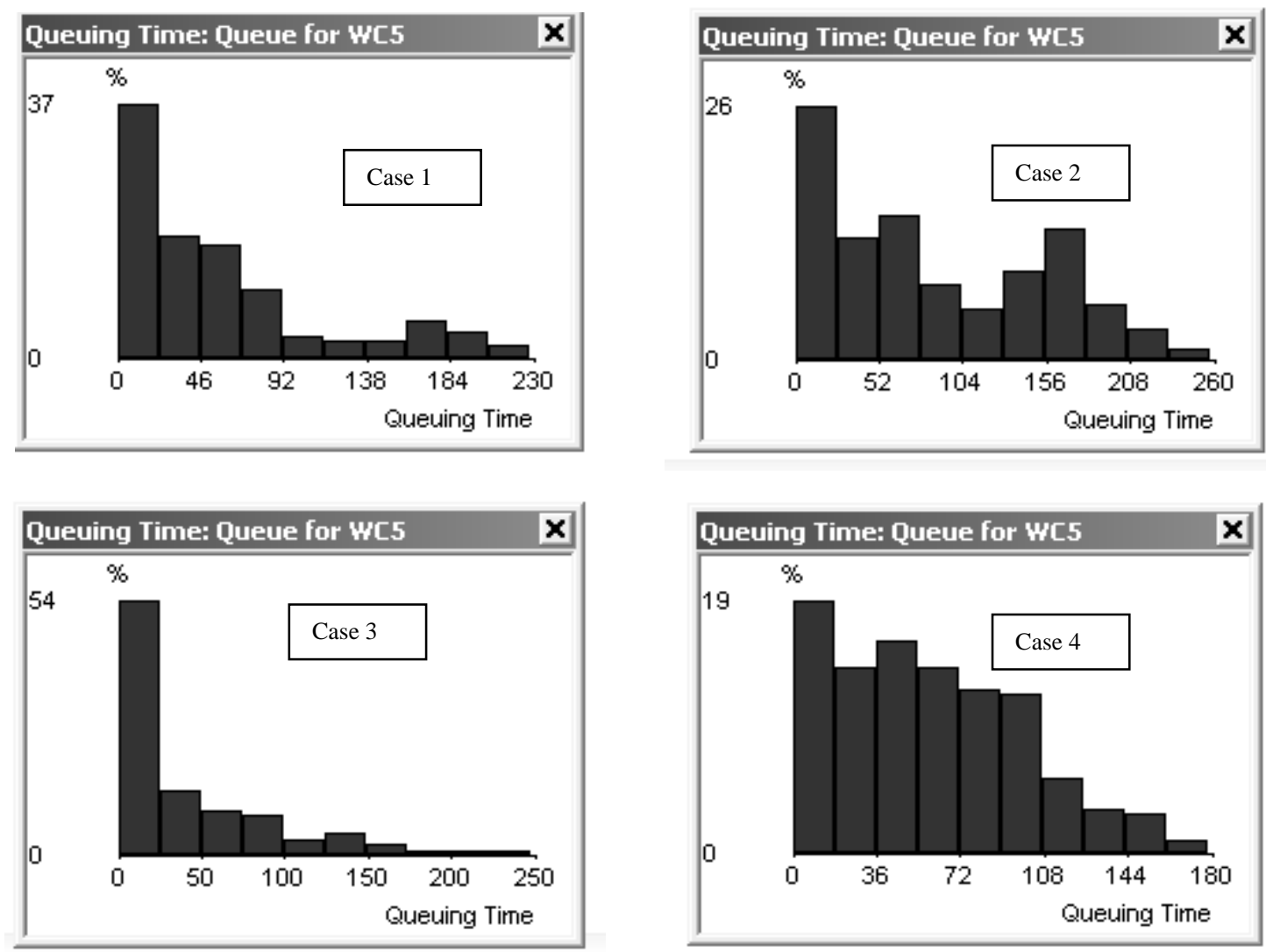

Figure 8: Queuing time comparison for Work Centre 5. 


\subsection{Work Centre Utilization}

It was noted in the results from Fig. 9 that the working percentage for work centres 5, 6 and 7 are lower than work centres 1, 2, 3, 4, 8 and 9, with the lowest being identified as $81.47 \%$ for Case 3. In all four cases the working percentage for work centre 6 seems extremely high and this condition was highlighted by the simulation result of $100 \%$ working. When comparing the four cases, Case 2 seems to have better work centre utilization than any other cases. This particular solution, however, generally highlights how the order release mechanism can be refined and managed to improve the work centre efficiency (utilization) without hindering supply chain performance.

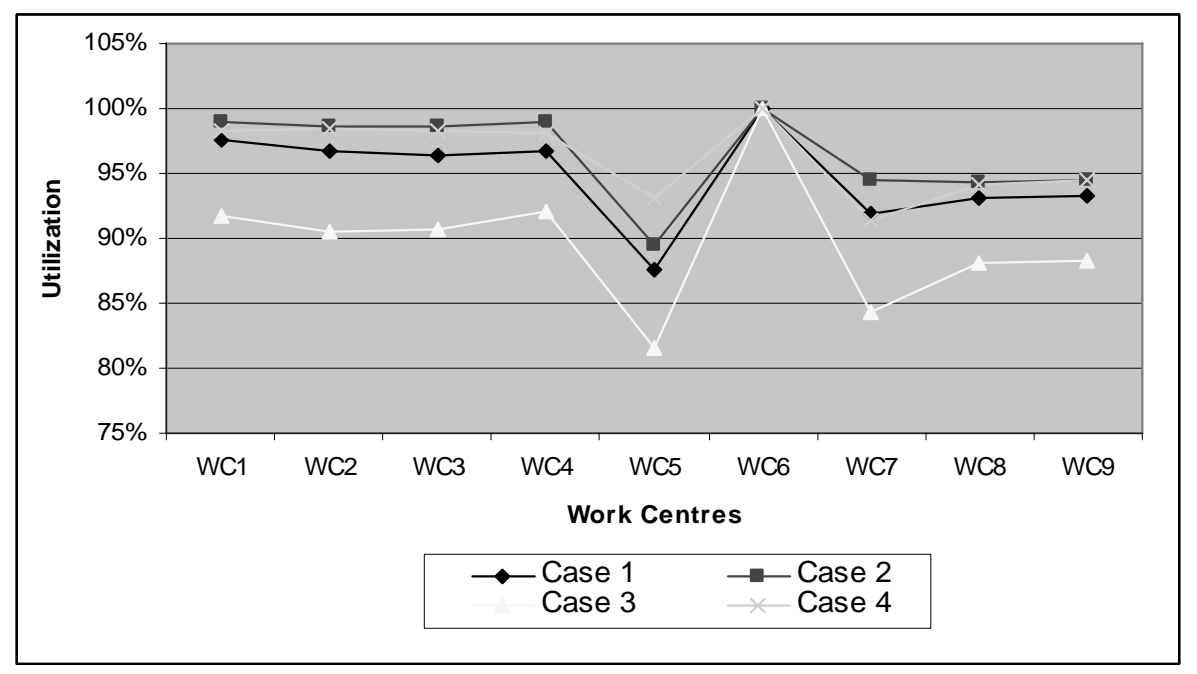

Figure 9: Comparison of Work Centre Utilization.

\section{CONCLUSIONS}

In this article, a holistic review of the supply chain has been conducted and the four order release mechanisms have been investigated. A novel aspect of the work presented in this paper is the modeling approach used to simulate the effect of the order release theory in the management of the supply network. The performance of an order release mechanism is evaluated and the simulation experiments indicate that Case 3 is the most superior order release mechanism when compared to other approaches.

With more advanced customization and speed of analysis comes the development of more detailed realistic dynamic models that more accurately resemble the dynamics of today's supply chain. These more realistic simulations can aid the development of more novel management techniques and highlight areas that could benefit from new information technologies, thus potentially creating tomorrow's supply chain for a company to maintain its position at the top of such a competitive and agile market.

\section{REFERENCES}

[1] GoldSim Technology Group LLC. Dynamic Simulation and Supply Chain Management, from http://www.goldsim.com/downloads/whitepapers/scmpaper.pdf, accessed on 14-06-07

[2] Hauge, J. W.; Paige, K. N. How Low Can You Go? Using Simulation to Determine Appropriate Inventory Levels, from http://www.novasim.com/downloads/howlowcanyougo.pdf, accessed 1406-07 
[3] Venkateswaran, J.; Son, Y. J.; Kulvatunyou, B. (2002). Investigation of influence of modeling fidelities on supply chain dynamics, Proceedings of the 2002 Winter Simulation Conference, 1183-1191

[4] Towill, D. R. (1991). Supply chain dynamics, International Journal of Computer Integrated Manufacturing, Vol. 4, No. 4, 197-208

[5] Archibald, G.; Karabakal, N.; Karlsson, P. (1999). Supply chain vs. supply chain: using simulation to complete beyond the four walls, Proceedings of the 1999 Winter Simulation Conference, 1207-1214

[6] Hafeez, K.; Griffiths, M.; Griffiths, J.; Naim, M. M. (1996). System design of a two-echelon steel industry supply chain, International Journal of Production Economics, Vol. 45, No. 1-3, 121-130

[7] Holmström, J. (1998). Business process innovation in the supply chain - a case study of implementing vendor managed inventory, European Journal of Purchasing Supply Management, Vol. 4, No. 2-3, 127-131

[8] Parija, G. R.; Sarker, B. R. (1999). Operations planning in a supply chain system with fixedinterval deliveries of finished goods, IIE Transaction, Vol. 31, No. 11, 1075-1082

[9] Yang, P.-C.; Wee, H.-M. (2001). An arborescent inventory model in a supply chain system, Production Plan Control, Vol. 12, No. 8, 728-735

[10] Cheung, K. L.; Leung, K. F. (2000). Coordinating replenishments in a supply chain with quality control considerations, Production Plan and Control, Vol. 11, No. 7, 697-705

[11] Zhao, X.; Xie, J. (2002). Forecasting errors and the value of information sharing in a supply chain, International Journal of Production Research, Vol. 40, No. 2, 311-335

[12] Klastorin, T. D.; Moinzadeh, K.; Son, J. (2002). Coordinating orders in supply chains through price discounts, IIE Transactions, Vol. 34, No. 8, 679-689

[13] Ertogral, K.; Wu, S. D. (2000). Auction-theoretic coordination of production planning in the supply chain, IIE Transactions, Vol. 32, No. 10, 931-940

[14] Qinghe, H.; Kumar, A.; Shuang, Z. (2001). A bidding decision model in multiagent supply chain planning, International Journal of Production Research, Vol. 39, No. 15, 3291-3301

[15] Dogan, K.; Goetschalckx, M. (1999). A primal decomposition method for the integrated design of multi-period production-distribution system, IIE Transactions, Vol. 31, No. 11, 1027-1036

[16] Korpela, J.; Kyläheiko, K.; Lehmusvaara, A.; Tuominen, M. (2002). An analytic approach to production capacity allocation and supply chain design, International Journal of Production Economics, Vol. 78, No. 2, 187-195

[17] Khouja, M. (2000). The economic lot and delivery scheduling problem: common cycle, rework, and variable production rate, IIE Transactions, Vol. 32, No. 8, 715-725

[18] Munson, C.; Rosenblatt, M. J. (2001). Coordinating a three-level supply chain with quantity discounts, IIE Transcations, Vol. 33, No. 5, 371-384

[19] Lee, H. Y.; Kim, S. H.; Moon, C. (2002). Production-distribution planning in supply chain using a hybrid approach, Production Plan Control, Vol. 13, No. 1, 35-46

[20] Agrawal, V.; Seshadri, S. (2000). Risk intermediation in supply chains, IIE Transactions, Vol. 32, No. 9, 819-831

[21] Karpak, B.; Kumcu, E.; Kasuganti, R. R. (2001). Purchasing materials in the supply chain: managing a multi-objective task, European Journal of Purchasing Supply Management, Vol. 7, No. 3, 209-216

[22] Persson, F.; Olhager, J. (2002). Performance simulation of supply chain designs, International Journal of Production Economics, Vol. 77, No. 3, 231-245

[23] Garg, A. (1999). An application of designing products and processes for supply chain management, IIE Transactions, Vol. 31, No. 5, 417-429

[24] Chan, F. T. S.; Chan, H. K. (2005). The future trend on system-wide modelling in supply chain studies, International Journal of Advanced Manufacturing Technology, Vol. 25, 820-832

[25] Crandall, R.; Burwell, T. (1993). The effect of work-in-process inventory levels on throughput and lead times, Production and Inventory Management, Vol. 34, 6-12

[26] Chan, F. T. S.; Humphreys, P.; Lu, T. H. (2002). Order release mechanisms in supply chain management: a simulation approach, International Journal of Physical Distribution \& Logistics Management, Vol. 31, No. 2, 124-139 
[27] Wu, Y.; Frizelle, G.; Ayral, L.; Marsein, J.; Van de Merwe, E.; Zhou, D. A. Simulation Study on Supply Chain Complexity in Manufacturing Industry, from http://www.ifm.eng.cam.ac.uk mcn/pdf files/part6 6.pdf, accessed on 14-6-07

[28] Ericsson, H. M. Managing the Construction Supply Chain by Simulation, Construction Informatics Digital Library, from http://itc.scix.net/paper ecce-2001-8content, accessed 14-6-07

[29] Sarjoughian, H. S.; Huang, D. P.; Godding, G. W.; Wang, W.; Rivera, D. E.; Kempf, K. G.; Mittelmann, H. D. (2005). Hybrid discrete event simulation with model predictive control for semiconductor supply-chain manufacturing, Proceedings of the 2005 Winter Simulation Conference, 256-265

[30] Petrovic, D. (2001). Simulation of supply chain behavior and performance in an uncertain environment, International Journal of Production Economics, Vol. 71, No. 1-3, 429-438

[31] Terzi, S.; Cavalieri, S. (2004). Simulation in the supply chain context: a survey, Computers in Industry, Vol. 53, 3-16

[32] Zeigler, B. P.; Praehofer, H.; Kim, T. G. (2000). Theory of modeling and simulation: integrating discrete event and continuous complex dynamic systems, Academic Press, San Diego

[33] Dong, M. (2001). Process modeling, performance analysis and configuration simulation in integrated supply chain network design, PhD Thesis, Virginia Polytechnic Institute and State University

[34] Hauge, J. W.; Paige, K. N. (2002). Learning SIMUL8: The Complete Guide, PlainVu Publishers, Bellingham

[35] Kuhl, F.; Weatherly, R.; Dahmann, J. (1999). Creating Computer Simulations: An Introduction to the High Level Architecture, Prentice-Hall, Upper Saddle River, NJ

[36] Bhaskaran, S. (1998). Simulation analysis of a manufacturing supply chain, Decision Sciences, Vol. 29, No. 3, 633-657

[37] Lambert, D. M.; Cooper, M. C.; Pagh, J. D. (1998). Supply chain management: implementation issues and research opportunities, International Journal of Logistics Management, Vol. 9, No. 2, $1-19$

[38] Riddalls, C. E.; Bennett, S. (2002). The stability of supply chain, International Journal of Production Research, Vol. 40, No. 2, 459-475

[39] Helo, P. T. (2000). Dynamic modeling of surge effect and capacity limitation in supply chains, International Journal of Production Research, Vol. 38, No. 17, 4521-4533

[40] Buchmeister, B. (2008). Investigation of the bullwhip effect using spreadsheet simulation, International Journal of Simulation Modelling (Int $j$ simul model), Vol. 7, No. 1, 29-41, doi:10.2507/IJSIMM07(1)3.093

[41] Orcun, S.; Uzsoy, R.; Kempf, K. (2006). Using system dynamics simulations to compare capacity models for production planning, Proceedings of the 2006 Winter Simulation Conference, 18551862 